\title{
Oral administration of an ethanolic extract of Hypericum gentianoides attenuates spontaneous colitis in $\mathrm{mdr}^{-\mathrm{a}^{-/-}}$mice
}

\section{Kelley M. K. Haarberg ${ }^{1}$, Meghan J. Wymore Brand ${ }^{1}$, Amanda E. Ramer-Tait ${ }^{2}$, Catherine C. Hauck ${ }^{3}$, Patricia A. Murphy ${ }^{3}$, Jesse M. Hostetter ${ }^{4}$, Michael J. Wannemuehler ${ }^{1 *}$}

${ }^{1}$ Department of Veterinary Microbiology and Preventive Medicine, College of Veterinary Medicine, Iowa State University, Ames, Iowa 50011, USA; ${ }^{2}$ Department of Food Science and Technology, University of Nebraska-Lincoln, Lincoln, Nebraska 68583, USA; ${ }^{3}$ Department of Food Science and Human Nutrition, Iowa State University, Ames, Iowa 50011, USA; ${ }^{4}$ Department of Veterinary Pathology, College of Veterinary Medicine, Iowa State University, Ames, Iowa 50011, USA

*Corresponding author: Michael J. Wannemuehler, $\mathrm{PhD}$, Professor, Department of Veterinary Microbiology and Preventive Medicine, College of Veterinary Medicine, Iowa State University, 2178 Vet Med, Ames, IA 50011, USA

Submission Date: March 10, 2016, Acceptance Date: May 24, 2016, Publication Date: May 30, 2016

\section{ABSTRACT \\ Background}

Nutraceuticals (i.e., complementary and alternative medicines) are gaining ground as therapeutic modalities for inflammatory and autoimmune disorders, primarily due to their low toxicity and high patient compliance. Several species of Hypericum have been shown to possess immunomodulatory capabilities in many disease models. However, the therapeutic potential of the chemically unique Hypericum gentianoides (HG) is largely untested. We investigated the efficacy of an orally administered ethanolic extract of HG (HGEE) to prophylactically inhibit/ameliorate the spontaneous colitis that develops in mdrla deficient $\left(\mathrm{mdr} \mathrm{a}^{-/-}\right)$mice.

\section{Methods}

Beginning at six weeks of age, vehicle ( $5 \%$ ethanol), HGEE $(4.8 \mathrm{mg} /$ day $)$ or metronidazole $(0.75$ $\mathrm{mg} / \mathrm{mL}$ ) were orally administered daily to $\mathrm{mdr} \mathrm{a}^{-/-}$or $\mathrm{FVB}^{\mathrm{WT}}$ mice until they reached 20 weeks of age or had lost $\geq 15 \%$ of their body weight. Macroscopic disease assessment included measurement of weight loss, colon shortening, and combined colonic/cecal macroscopic lesion scores. Colonic/cecal inflammation was also scored histologically. Inflammatory responses were assessed using myeloperoxidase (MPO) assay and analysis of serum cytokines/chemokines.

\section{Results}

Daily administration of HGEE significantly $(p<0.05)$ delayed the onset of clinical signs of disease, reduced the associated morbidity, and attenuated macroscopic and microscopic disease/inflammatory scores in $\mathrm{mdr} \mathrm{a}^{-/-}$mice. After 14 weeks of treatment, there were no adverse 
macroscopic or microscopic effects observed following the daily administration of HGEE to wild type FVB mice. Histological evaluation of colonic tissue revealed a decrease in neutrophil infiltration in HGEE treated mdr $1 \mathrm{a}^{-/-}$mice, which was substantiated by a significant decrease $(\mathrm{p}$ $\leq 0.05$ ) in colonic MPO activity. Compared to vehicle treated mdr1a ${ }^{-/-}$mice, levels of G-CSF, $\mathrm{KC}$, and $\mathrm{TNF} \alpha$ were significantly lower in the serum of mdr $1 \mathrm{a}^{-/-}$mice treated with HGEE.

\section{Conclusions}

Oral administration of HGEE was shown to be safe, effectively ameliorating mucosal inflammation and disease severity in $\mathrm{mdrla}^{-/-}$mice. The attenuation of mucosal inflammation correlated with a reduction in the production of pro-inflammatory cytokines and the recruitment of inflammatory granulocytes to the intestinal mucosa, which suggests that extracts of $H$. gentianoides have the potential to be used as a CAM product for mucosal inflammation.

Keywords: Hypericum gentianoides, colitis, IBD, mdrla deficient mice, botanical

\section{BACKGROUND}

Inflammatory bowel disease (IBD) is complex and multifactorial, with a poorly defined etiology [1]. The two predominant forms of IBD, ulcerative colitis and Crohn's disease, are both characterized by relapsing mucosal inflammation [2]. A 2007 study found that the prevalence of adult Crohn's disease and ulcerative colitis in the United States was 238 and 201 per 100,000 individuals respectively. Additionally, the pediatric prevalence of these diseases was 43 per and 28 per 100,000 individuals respectively [3]. The incidence of IBD is increasing in developing countries where new biologic therapies are very expensive and not readily available [4, 5]. Because the underlying etiology of IBD is unknown, clinicians focus on and treat the symptoms of IBD. The most popular and effective therapeutics consist of mesalazines (e.g., 5aminosalicylic acid), corticosteroids, and anti-TNF $\alpha$ antibodies which are often hindered by difficulties in dose titration, toxicity, low patient tolerance and compliance, and delayed activity, as well as the occurrence of side-effects such as secondary infections [6, 7]. Additionally, the long-term benefits of biologic therapies are still unclear and patients can become refractory to these treatments. In the case of anti-TNF $\alpha$ antibody therapies, 20 to 40 percent of IBD patients eventually fail to respond to treatment and fail to respond to a switch in anti-TNF $\alpha$ reagent [8$12]$.

In increasing numbers, physicians and their patients are adding natural products as therapeutic adjuncts to their medication regimen to directly treat disease or to alleviate the side effects of primary therapies [13]. It has been estimated that up to 50 percent of patients suffering with IBD in North America utilize some form of complementary and alternative medicine (CAM) $[14,15]$. Herbal supplementation is one of the most popular forms of CAM utilized by IBD patients worldwide [15]. While the use of CAM is increasing worldwide, they are underrepresented in high-impact pre-clinical studies, clinical trials, and medical education programs [16]. At the same time, over half of all pharmaceuticals developed in the last few decades arose from naturally occurring compounds [17]. Complex plant extracts have the advantages of containing various combinations of anti-inflammatory, anti-bacterial, anti-viral, and antioxidant compounds, while being less costly and inducing fewer toxic side effects due to 
synergy between chemical compounds $[18,19]$. Recently it was demonstrated that an ethanolic extract of Prunella vulgaris attenuated the severity of spontaneous colitis in mdr1a ${ }^{-/-}$mice [20].

It has been recognized that consumption of selected species of Hypericum or their extracts could be therapeutically or prophylactically efficacious in the treatment of IBD due to their use in treating gastrointestinal illness, as well as reported anti-inflammatory, analgesic, wound healing, and free radical inhibitory effects [21-25]. The chemical constituents of the most commonly known species of this genus, Hypericum perforatum (common name, St. John's Wort), are well defined and include several flavonoids: quercetin, hyperoside, isoquercitrin, quercitrin, rutin, and amentoflavone [26, 27]. Of these compounds, rutin has been shown to ameliorate experimental colitis [28]. $H$. perforatum has been demonstrated to attenuate TNBSinduced colitis in rats [29]. H. perforatum contains the phenols caffeic acid and chlorogenic acid, in addition to tannins. Caffeic acid has been shown to modulate the IL-12/IL-23 pathway, while proanthocyanidins inhibit NFKB activity [30,31]. The bioactive compounds that have received the most attention in $H$. perforatum are the photoactive compounds hypericin and pseudohypericin, as well as hyperforin [32]. While the biological activity, including antiinflammatory activity, of these three components have been evaluated, they can also cause photosensitivity and toxicity in animals and humans making $H$. perforatum less attractive as a medicinal plant [33-35].

While the species $H$. gentianoides (HG) is dispersed throughout the eastern United States, their biochemical and medicinal properties are not well documented. However, it is known that HG has been used by Native Americans to reduce gastrointestinal illness and fever and to speed wound healing. This leaves one to speculate the ability of HG to have beneficial effects with respect to ameliorating mucosal inflammation associated with IBD [36]. Compared to other species of Hypericum, the chemical composition of $\mathrm{HG}$ is unique in that it contains the antibacterial compounds uliginosin $\mathrm{A}$ and $\mathrm{B}$, but lacks hypericin, pseudohypericin, and hyperforin $[37,38]$. This suggests that HG extracts would have fewer toxic side effects when compared to other Hypericum species. It was previously shown that an extract of HG reduced prostaglandin E2 production by stimulated RAW 264.7 macrophage cells with no significant cytotoxicity [39]. Neither HG nor any extracts of HG have been evaluated for biologic activity in vivo. In this study, we evaluate the anti-inflammatory and immunomodulatory activities of HG ethanolic extract (HGEE) in the mdr1a ${ }^{-/-}$mouse model of spontaneous colitis. Based on the recently reported chemical composition of $\mathrm{HG}[37,38]$, the ability to reduce inflammatory prostaglandin synthesis and the anti-inflammatory activity, it was hypothesized that HGEE will reduce the severity of mucosal inflammation associated with the onset of spontaneous colitis. The results of this study demonstrate that the daily administration of HGEE ameliorated the severity of colitis that naturally develops in $\operatorname{mdr} 1 \mathrm{a}^{-/-}$mice.

\section{METHODS}

\section{Hypericum gentianoides extract preparation}

HG dried plant materials were kindly provided by Dr. Mark Wiederlichner at the USDA-ARS North Central Regional Plant Introduction Station (NCRPIS, Ames, IA). 10\% buffered formalin, $30 \%$ hydrogen peroxide, and concentrated sulfuric acid, were purchased from Fisher Scientific (Fair Lawn, NJ). Information about the specific provenance of HG accession Ames 28015, 
obtained from the NCRPIS, is available on the Germplasm Resources Information Network database at http://www.ars-grin.gov/npgs/acc/acc_queries.html. Arboreal portions of plants from HG (Ames 28015), harvested in 2009, were prepared for storage by drying for 8 days at $38^{\circ} \mathrm{C}$ in a forced-air dryer with constant humidity. The dried material was ground with a 40-mesh screen and stored at $-20^{\circ} \mathrm{C}$ until extraction. Extractions were made in $95 \%$ ethanol $(\mathrm{EtOH})$ solvent by the Soxhlet method [27]. Upon complete drying of the extract by evaporation, the weight of the extracted material was recorded; the residue was lyophilized and stored at $-20^{\circ} \mathrm{C}$ until solubilized in a final working solution of 5\% EtOH (the lowest concentration of EtOH that would allow solubilization) at a final plant extract concentration of $24 \mathrm{mg} / \mathrm{mL}$. As previously described, the dose of HGEE used in these studies was based upon the dose of Hypericum perforatum (i.e., St. John's Wort) used in humans and adjusted 10-fold to be metabolically equivalent for use in mice [40]. The working HGEE was divided into $2 \mathrm{~mL}$ aliquots and stored at $-20^{\circ} \mathrm{C}$ until use. $\mathrm{HG}$ extracts from NCRPIS were screened for endotoxin by using the Limulus Amebocyte Lysate Test (BioWhittaker, Inc., Walkersville, MD) according to manufacturers' specifications, and there was no detectable endotoxin present in the extract (data not shown).

\section{Animals}

All animal experiments were approved by the Institutional Animal Care and Use Committee at Iowa State University. Four to five week old male mdr1a ${ }^{-/-}$FVB.129P2-Abcb1a tm1BorN7 and wild type (WT) FVB.129P2 mice were obtained from Taconic Farms, Inc. (Germantown, NY). Animals were housed and maintained in the Laboratory Animal Resource facility at the College of Veterinary Medicine, Iowa State University. Established specific pathogen-free husbandry practices were followed and twelve-hour light/dark cycles were applied. Upon arrival, mice were fed a defined Harlan Teklad AIN93 (M) rodent chow (Madison, WI) to control the amount of phytochemicals in their diet. Food and water was provided ad libitum.

\section{Experimental Design}

A total of six treatment groups of mice were utilized: groups 1 and 2) $\mathrm{mdr}^{-/ /}$and $\mathrm{FVB}^{\mathrm{WT}}$ mice were orally gavaged with $4.8 \mathrm{mg}$ /day HGEE extract in a $200 \mu \mathrm{L}$ volume (prepared as described above); groups 3 and 4) $\mathrm{mdrla}^{-/}$and $\mathrm{FVB}^{\mathrm{WT}}$ mice were orally gavaged with $200 \mu \mathrm{L} 5 \% \mathrm{EtOH}$ vehicle and given drinking water (refreshed weekly) containing $0.75 \mathrm{mg} / \mathrm{mL}$ metronidazole (Sigma, St. Louis, MO); groups 5 and 6) $\mathrm{mdr} \mathrm{a}^{-/-}$and $\mathrm{FVB}^{\mathrm{WT}}$ mice were orally gavaged with $5 \%$ EtOH vehicle alone. $\mathrm{N}=4$ to 10 mice per group per experiment. Gavage was performed using a 20 gauge feeding needle once a day beginning at 6 weeks of age until the mice reached twenty weeks of age, or were removed from the study because of weight loss exceeding $15 \%$ of their peak body weight. At necropsy, mice were euthanized by $\mathrm{CO}_{2}$ asphyxiation. Following euthanasia, blood was collected by cardiac puncture and sections of ceca and proximal colon were excised, washed, and stored for further histological and MPO enzymatic analysis. Serum was analyzed by multiplex assay to measure cytokine and chemokine levels.

\section{Macroscopic typhlocolitis assessment}

Following euthanization, the colon and cecum were excised, photographed, colon length was measured, and macroscopically scored for lesions severity. Gross typhlocolitic lesions were 
scored using a nine-point additive scale: a score of zero being a healthy colon and a score of 9 being a maximally diseased colon. Score parameters evaluated included: 1) cecal atrophy, 2) presence of an enlarged cecal tonsil or other enlarged lymphoid aggregates, 3) cecal emptying, 4) watery or mucoid intraluminal cecal and/or colonic contents, 5) bloody cecal contents, 6) bloody colonic contents, 7) visible thickening and rigidity of the cecum, 8) visible thickening and rigidity of the colon, and 9) absence of formed fecal pellets in the colon.

\section{Histopathological assessment}

Sections of excised cecum and proximal colon were placed in $10 \%$ buffered formalin, paraffin embedded, sectioned, and routinely stained with hematoxylin and eosin. Stained colonic and cecal sections were blindly scored by a board certified pathologist (Dr. Jesse Hostetter, Iowa State University, Ames, IA) as previously described [20, 41, 42]. Microscopic mucosal lesion scores were based on five separate parameters, with each parameter scored on a scale of 0 to 5 ( 5 = maximum severity). Score parameters include: 1) ulceration of the mucosa; 2) extent of inflammatory cell infiltrate; 3) mucosal edema characterized by the extent of lymphatic and vascular distortion from the normal architecture; 4) stromal collapse and necrosis of the glands; 5) glandular hyperplasia characterized by the distribution of enterocytes along the base of the gland; and additionally mucosal height (measured by optical micrometer) was added to generate additive tissue score. Additionally, the character of the inflammatory infiltrate was also recorded.

\section{Myeloperoxidase assay}

Myeloperoxidase (MPO) activity was used as a measure of neutrophil/granulocyte accumulation in proximal colonic and cecal tissues. The MPO assay was performed as previously described $[20,43]$. Briefly, proximal colon and cecal sections were collected at necropsy and FVB ${ }^{\mathrm{WT}}$ mouse serum was used for a positive control. Tissue was trimmed to approximately $35 \mathrm{mg}$, homogenized, and then the recovered cells were enumerated. Afterwards, the cells were sonicated, cellular debris was removed by centrifugation, and the supernatant fluid was collected and analyzed for total protein. Individual lysates were analyzed in triplicate by adding 3,3 ',5,5'tetramethylbenzidine dihydrochloride hydrate, followed immediately hydrogen peroxide (5 mM). After two minutes, sulfuric acid was added to stop the reaction and the optical density was measured at $405 \mathrm{~nm}$ using SOFTmax PRO 4.0 (V-Max, Molecular Devices, USA). The MPO content was determined by comparison to the standard curve and MPO activity was expressed as the relative units of enzyme activity per gram of wet weight of tissue.

\section{Serum cytokine quantification}

Following euthanization of $\mathrm{mdr} 1 \mathrm{a}^{-/-}$and $\mathrm{FVB}^{\mathrm{WT}}$ mice, blood was collected via cardiac puncture. The blood was allowed to clot for 24 hours at $4{ }^{\circ} \mathrm{C}$ after which samples were centrifuged at $10,000 \times \mathrm{g}$ for 10 minutes. Serum was then removed and stored at $-20{ }^{\circ} \mathrm{C}$ until use. The day of assay, serum samples were thawed to room temperature. Concentrations of cytokines and chemokines of interest were measured using the Milliplex mouse cytokine-chemokine 32-plex multiplexed flow-cytometric assay kit (EMD Millipore, Billerica, MA). Analytes screened include: Eotaxin, G-CSF, GM-CSF, IFN- $\gamma$, IL-10, IL-12 (p40), IL-12 (p70), IL-13, IL-15, IL17, IL-1 $\alpha$, IL-1 $\beta$, IL-2, IL-3, IL-4, IL-5, IL-6, IL-7, IL-9, CXCL10, KC, LIF, LIX, M-CSF, 
MCP-1, CXCL9, MIP-1 $\alpha$, MIP-1 $\beta$, MIP-2, RANTES, TNF $\alpha$, VEGF. The assay was performed according to the manufacturer's instructions. Individual serum samples were diluted 1:1 in supplied assay buffer. The pre-conjugated multiplex analyte beads were added to each well and the samples were incubated at $4{ }^{\circ} \mathrm{C}$ overnight on a plate shaker (Barnstead International Titer Plate Shaker, setting \#5, Model \#4625). Following vacuum filtration and washing, the detection

antibody was added to all the wells and the plate was incubated at room temperature while shaking for two hours. The streptavidin-phycoerythrin was then added to each well and incubated for 30 minutes at room temperature while shaking. After a final vacuum filtration and rinse, the beads were resuspended in sheath fluid and the mean fluorescence intensity was measured using Luminex platform technology (The FlowMetric System, Luminex, Austin, TX). Mean fluorescence intensity values were subsequently converted to concentrations using a 5parameter logistic or line curve-fitting method in MasterPlex QT Software (MiraiBio Group, San Francisco, CA).

\section{Statistical analysis}

All data, except survival curves, were evaluated by the Kruskal-Wallis test with Dunn's multiple comparisons test. Statistically non-significant differences in the $\mathrm{mdr}^{-1 /} \mathrm{a}^{-/}$groups were further evaluated by the Mann-Whitney test for ordinal data and unpaired $t$-test with Welch's correction for continuous data. Survival curves were evaluated by the Log-rank (Mantel-Cox) test. A pvalue of $<0.05$ was considered statistically significant. Prism 6 was used for all statistical calculations.

\section{RESULTS AND DISCUSSION}

The ethanolic extract of Hypericum gentianoides delays the onset of severe colitis and

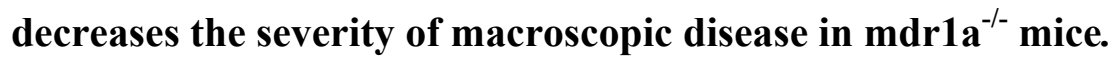

Previously published data demonstrates that $\mathrm{mdr} \mathrm{a}^{-/-}$mice spontaneously develop colitis between 8 and 36 weeks of age, with the average age of disease onset being 20 weeks [44]. Wilk and colleagues have demonstrated that the expression of proinflammatory cytokines is upregulated as early as two weeks of age in mdrla ${ }^{-/-}$mice [45]. Mice that are deficient in mdrla are also genetically more susceptible to barrier disruption resulting in the increased exposure of the lamina propria to phlogistic components present in the lumen of the gut $[44,45]$. The $\mathrm{mdr}^{-1 /} \mathrm{a}^{-/}$ mouse model is characterized by an increase in colonic inflammation that begins to develop by 8 weeks of age [44]. The inflammation becomes transmural, multifocal, and is characterized by the production of multiple inflammatory cytokines and chemokines [46, 47]. The underlying mechanism associated with the onset of colitis in this model as well as the genetic basis for the onset of colitis are consistent with some forms of human IBD, adding to the relevance of this model in screening CAM products (e.g., botanical extracts) as potential therapeutic or prophylactic modalities for IBD $[48,49]$.

The current study is novel due to its evaluation of the in vivo medicinal benefits of orally administering an extract derived from Hypericum gentianoides in the context of a spontaneous model of murine colitis. Using the $\mathrm{mdr} \mathrm{a}^{-/-}$model of spontaneous murine colitis, we evaluated the anti-inflammatory efficacy of oral HGEE in comparison to vehicle (5\% ethanol in PBS) alone. As shown in Figure 1, the timeframe and severity of colitis in vehicle-treated $\mathrm{mdr} \mathrm{a}^{-/-}$ 
mice was consistent with that reported in previous studies [44, 45]. As expected, FVB ${ }^{\mathrm{WT}}$ mice treated with either the HGEE or the vehicle alone remained free of colitis (data not shown). As a positive control, a separate group of $\mathrm{mdr}^{-\mathrm{a}^{-/}}$mice was treated with metronidazole in there drinking water. As expected, the metronidazole treatment significantly $(\mathrm{p} \leq 0.05)$ reduced the onset of clinical disease (Figure 1) and the development of microscopic inflammation (data not shown). Only two metronidazole-treated mdrla $\mathrm{a}^{-/ 2}$ mice developed clinical signs of disease, albeit mild, underscoring the importance of the resident microbiota in the pathogenesis of colitis that develops in the $\operatorname{mdr} 1 \mathrm{a}^{-/-}$mice [44].

To determine the effectiveness of HGEE as a treatment for spontaneous colitis, six-week old mdrla $\mathrm{a}^{-/-}$mice were gauaged once daily with vehicle or $4.8 \mathrm{mg}$ HGEE. As anticipated, the majority of vehicle treated $\mathrm{mdr} \mathrm{a}^{-/-}$mice (11 out of $16,68.8 \%$ ) developed severe colitis prior to 20 weeks of age. In contrast, only 6 of the 16 (i.e., $37.5 \%$ ) HGEE treated mice developed clinical signs of colitis (i.e., $\geq 15 \%$ weight loss) prior to reaching 20 weeks of age such that they were removed from the study (Figure 1). HGEE treatment markedly delayed the onset of morbidity by approximately 33 days when compared to vehicle treated $\mathrm{mdr}^{-\mathrm{a}^{-/-}}$mice and the attenuation of clinical signs of disease in the HGEE treated $\mathrm{mdr}^{-a^{-/}}$mice was significant $(\mathrm{p}<0.05)$ when compared to vehicle treated $m \mathrm{mr}^{-\mathrm{a}^{-/}}$mice. This observation suggests that HGEE may be used as an adjunct therapy for gastrointestinal inflammation and would be consistent with the current (i.e., popular) use of CAM products $[14,15]$.

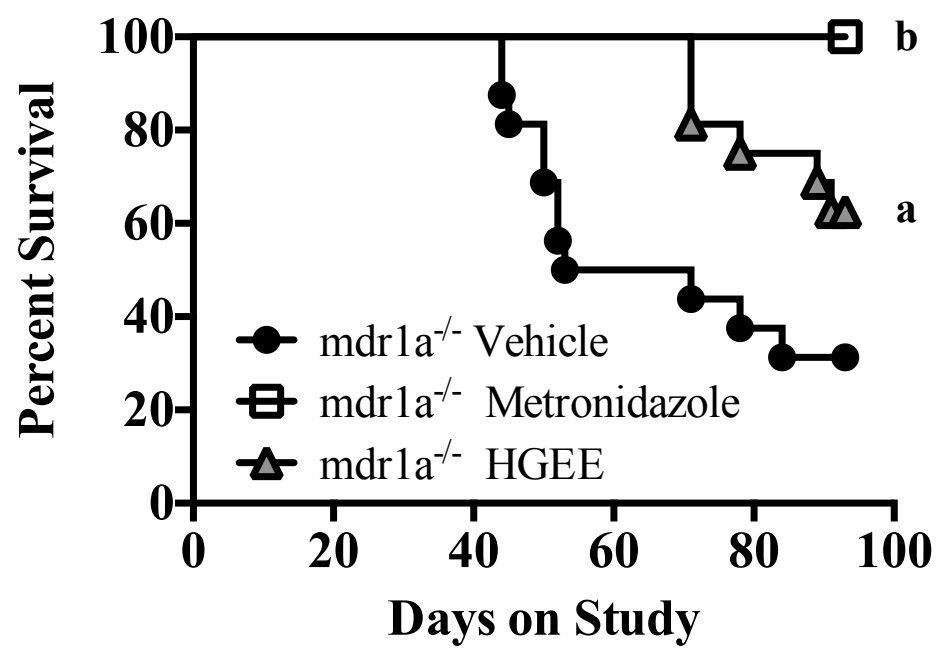

Figure 1 The percent of mdrla $\mathrm{a}^{-/-}$mice remaining on study over time. Mdrla $\mathrm{a}^{-/-}$mice were removed from the study as they developed significant clinical signs of disease (i.e., $\geq 15 \%$ loss of body weight) or at 20 weeks of age (i.e., the termination of the experiment) as described in methods. ${ }^{a} \mathrm{p}<0.05,{ }^{\mathrm{b}} \mathrm{p}<0.01$ as compared to vehicle treated mdr1 $\mathrm{a}^{-/}$mice using a nonparametric analysis with a Kruskal-Wallis post hoc test. This adapted survival curve is representative of two separate experiments (vehicle $n=16$, metronidazole $n=10$, HGEE $n=16$ ).

While the HGEE treated $\mathrm{mdr}^{-/ \mathrm{a}^{-/}}$mice had a better clinical outcome than vehicle treated mdr1a ${ }^{-/-}$mice, it was essential to evaluate the gastrointestinal tract for severity of marcoscopic and microscopic lesions. Representative photographs of ceca and colons (Figure 2) show the extent of macroscopic tissue changes that developed in vehicle treated $\mathrm{mdr}_{1 \mathrm{a}}{ }^{-/-}$mice. In these 
mice, it was readily apparent that the ceca were atrophied with visible, prominent cecal tonsils suggestive of local immune activation and inflammation. It was also noted that there was a decrease in the amount of cecal and colonic contents and that both cecal and colonic tissues were notably thickened. In the mdr $1 \mathrm{a}^{-/-}$mice, blood was often observed in cecal and colonic contents and formed fecal pellets were absent. Conversely, the ceca and colons of HGEE treated mdr $1 \mathrm{a}^{-/-}$ mice were markedly improved and closely resembled the gastrointestinal tract of healthy FVB ${ }^{\mathrm{WT}}$ mice. The cecal and colonic tissues of $\mathrm{mdr}^{-/ /}$mice treated with metronidazole also healthy and all of the antibiotic treated mice survived to the end of the experiment (Figure 1).

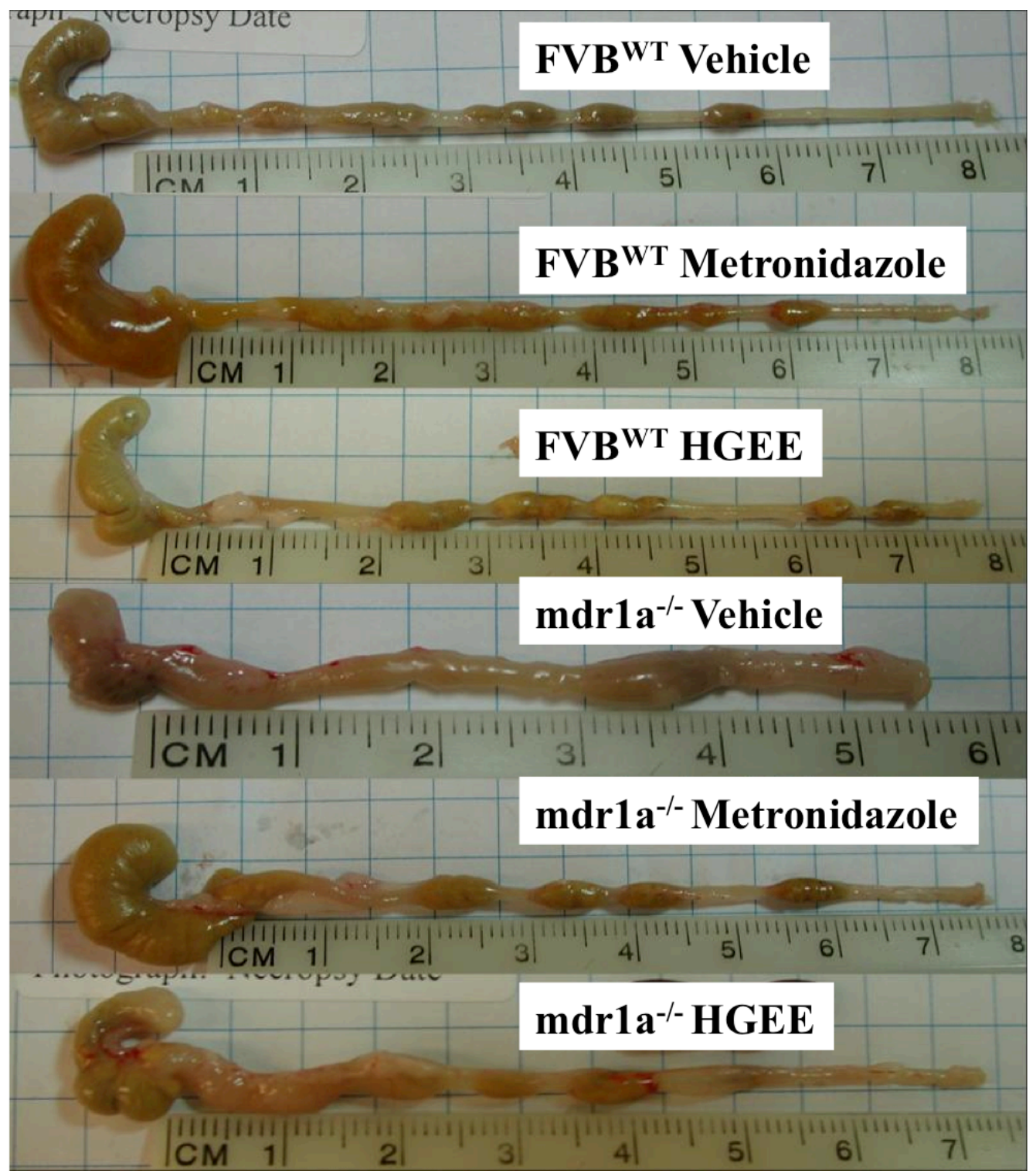

Figure 2 Photographs of colons and ceca from WT or $\mathrm{mdrla}^{-/-}$mice treated with vehicle, metronidazole or HGEE. Mdr1a ${ }^{-/-}$mice were gavaged with $5 \%$ EtOH vehicle $(\mathrm{n}=16), 0.075$ $\mathrm{mg} / \mathrm{mL}$ metronidazole dosed in drinking water $(\mathrm{n}=10)$ or gavaged with $4.8 \mathrm{mg} \operatorname{HGEE}(\mathrm{n}=16)$ daily as described in methods. $\mathrm{FVB}^{\mathrm{WT}}$ mice were also represented in each treatment group $(\mathrm{n}=$ $6, \mathrm{FVB}^{\mathrm{WT}}$ mice per treatment). Images are representative of two independent experiments. 
Macroscopically, severe typhlocolitis (a score $\geq 5$ ) was observed in $75 \%$ of vehicle treated mdrla ${ }^{-/-}$mice compared to only $25 \%$ of HGEE treated $\mathrm{mdrla}^{-/-}$mice (Figure $3 \mathrm{~A}$ ). All vehicle treated mdrla $\mathrm{a}^{-/-}$mice displayed at least mild macroscopic disease, while all of the macroscopic scores for HGEE treated mdr $1 \mathrm{a}^{-/-}$mice are below the median score of the vehicle treated mdr1a $\mathrm{a}^{-/-}$ mice (Figure 3A). HGEE treatment significantly $(\mathrm{p}<0.01)$ attenuated the severity of macroscopic disease when compared to vehicle treatment in $\mathrm{mdr}^{-\mathrm{a}^{-/}}$mice. While not statistically significant, there was a trend that colon lengths in HGEE treated $\mathrm{mdr}^{-\mathrm{a}^{-/}}$mice were less affected when compared to vehicle treatment (Figure 3B) which supports the significant differences noted for the overall macroscopic scores. (Figure $3 \mathrm{~A}$ ). As expected, no $\mathrm{FVB}^{\mathrm{WT}}$ mice exhibited any clinical signs of disease or any microscopic lesions regardless of the administration of HGEE or not (Figure 3, A and B).
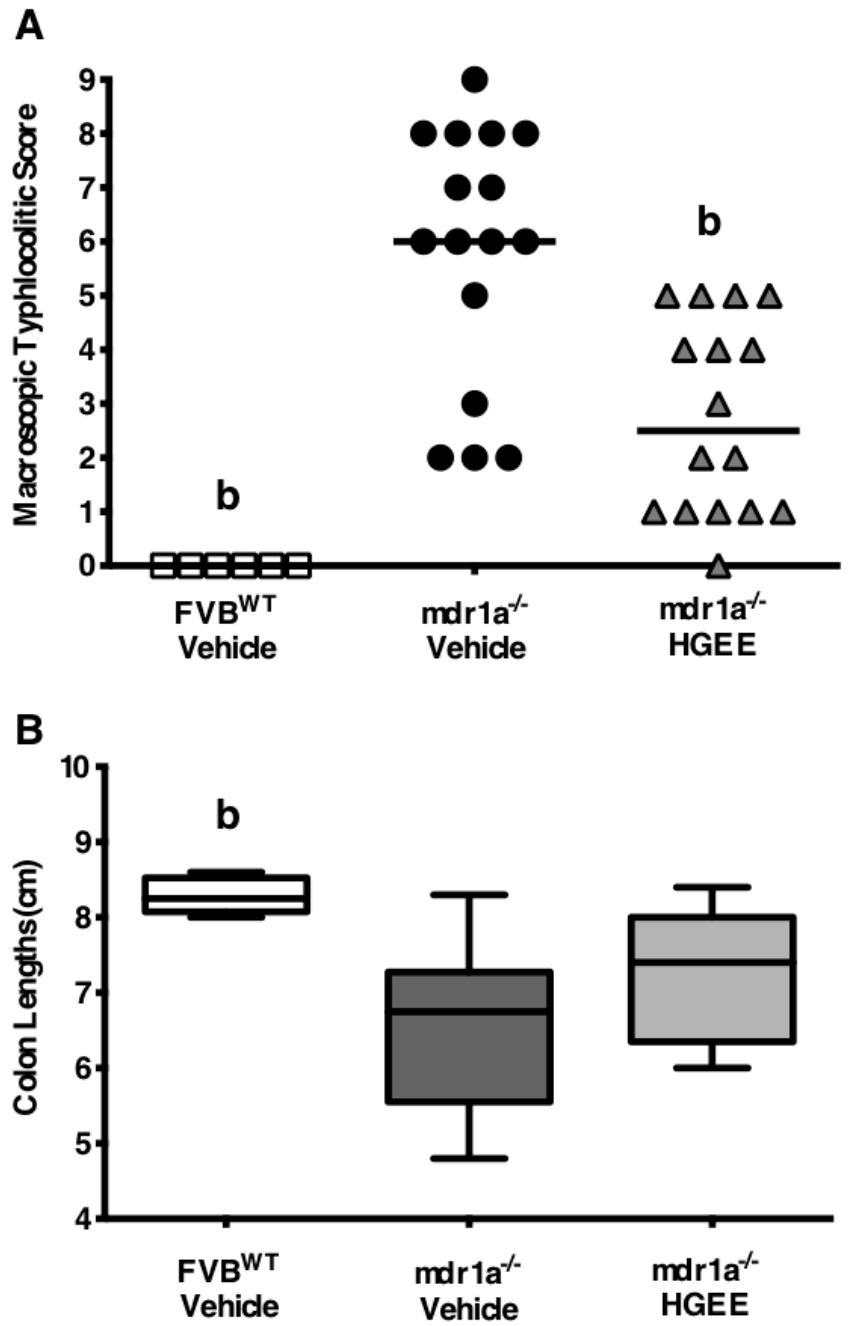

Figure 3. Macroscopic assessment of colitic severity. A) Macroscopic typhlocolitic scores at necropsy as described in methods $(\mathrm{Max} / \mathrm{Severe}=9$, Min/Healthy $=0$.) B) Colon lengths of $\mathrm{mdrla}^{-/}$and $\mathrm{FVB}^{\mathrm{WT}}$ mice treated with vehicle, metronidazole or HGEE were measured at necropsy and the group range is represented. Whiskers indicate minimum and maximum values, while the horizontal line represents the group median. Data is representative of two independent experiments; $\mathrm{FVB}^{\mathrm{WT}}$ vehicle treated mice $(\mathrm{n}=6), \mathrm{mdr}^{-\mathrm{a}^{-/}}$vehicle treated $(\mathrm{n}=16)$, and $\mathrm{mdr} 1 \mathrm{a}^{-/-}$ HGEE treated $(n=16) .{ }^{b} p<0.01$ as compared to $m d r 1 a^{-/-}$vehicle with a Kruskal-Wallis test. 


\section{Impact of $\boldsymbol{H}$. gentianoides treatment on the severity of histopathological lesions}

Histological inflammation of cecal and colonic tissues was scored based on changes in mucosal height, ulceration, extent and character of inflammatory cell infiltrate, edema, stromal collapse and glandular necrosis, and glandular hyperplasia (Tables 1 and 2). Both the colons and ceca of vehicle treated mdrla ${ }^{-/-}$mice were characterized by crypt hyperplasia, extensive transmural ulceration and inflammatory infiltrate, as well as occasional submucosal edema and stromal collapse (Table 1 and Figure 4). HGEE treated mdrla $^{-/-}$mice exhibited significant $(\mathrm{p}<0.05)$ improvement in colonic neutrophil infiltration (Table 1), cecal ulceration, stromal collapse, and an overall lower cecal score related to the severity of mucosal inflammation (Table 2). As expected, tissues from vehicle-treated $\mathrm{FVB}^{\mathrm{WT}}$ mice did not exhibit signs of inflammation. Significantly, HGEE treatment of $\mathrm{FVB}^{\mathrm{WT}}$ mice did not induce any adverse toxic or inflammatory responses (data not shown). While $100 \%$ of vehicle treated $m \mathrm{dr}^{-/ /} \mathrm{a}^{-/}$mice exhibited extensive neutrophilic infiltration into the colonic and cecal mucosa, inflammatory cells were absent in 31 $\%$ and $44 \%$ colons and ceca of HGEE treated $\mathrm{mdr} \mathrm{a}^{-/-}$mice, respectively (Tables 1, 2 and Figure 4). The ceca from vehicle-treated $\mathrm{FVB}^{\mathrm{WT}}$ mice were characterized by normal mucosal architecture and height, intact colonic glands, little to no mucosal or submucosal edema, and normal resident populations of mononuclear cells, including a sparse number of plasma cells. In contrast, ceca from diseased $\mathrm{mdr} 1 \mathrm{a}^{-/-}$exhibited mucosal and glandular hyperplasia, transmural ulceration and inflammation, as well as stromal necrosis and a marked increase of inflammatory cells mostly comprised of neutrophils. The histopathological lesions in the ceca and colon of HGEE treated mdr1 $\mathrm{a}^{-/-}$mice were less severe $(\mathrm{p}<0.05)$ and appeared similar to the tissue from the $\mathrm{FVB}^{\mathrm{WT}}$ mice. An increase in the presence of plasma cells in the cecal mucosa was noted in mdr1a $\mathrm{a}^{-/-}$mice treated with HGEE. Because of the genetic underpinnings of the disease in mdr1a $\mathrm{a}^{-/-}$ mice, it is not surprising that the HGEE treatment did not prevent the onset of colitis; however, HGEE treatment did significantly ameliorate macroscopic and microscopic lesions in mdr $1 \mathrm{a}^{-/-}$ mice when compared to vehicle treated $\mathrm{mdrla}^{-/-}$mice. While longer studies would be required, these results suggest that oral administration of HGEE could be used to reduce the morbidity (i.e., improved Disease Activity Index) of these treated mice.

The absence of clinical disease in HGEE treated $\mathrm{mdr}^{-1 /} \mathrm{a}^{-/}$mice correlated with the presence of mild to moderate microscopic cecal ulceration and mucosal necrosis, as well as an overall lower histopathological score in these mice (Figure 4, Tables 1 and 2). These lower (i.e., attenuated) microscopic and macroscopic disease scores observed in the HGEE treated mdr1a ${ }^{-/-}$ mice could be attributed to the significant reduction in the neutrophilic infiltration into the cecal and colonic mucosa of these mice (a $25 \%$ and $31 \%$ improvement, respectively). MPO activity, a known contributor to and marker of inflammation, was similarly reduced in the colons and ceca of HGEE treated mdrla ${ }^{-/-}$mice [50-52]. Tissue damage due to excessive neutrophil infiltration and activation is known to contribute to disease severity in IBD [53-57]. A greater number of microscopic parameters were improved in the ceca of HGEE treated mdrla $\mathrm{a}^{-/-}$mice. However, the reduction in neutrophil infiltrate and subsequent MPO activity was less dramatic in the cecal 
tissues than in the colons of these mice. This may indicate that the recruitment and accumulation of neutrophils played an important role in the severity of lesion development but was not the only inflammatory parameter affected by HGEE that contributed to the amelioration of colitis in these treated mdrla $\mathrm{a}^{-/-}$mice.

The trend for increased presence of plasma cells observed histologically in the colons and ceca of HGEE treated $\mathrm{mdr} \mathrm{a}^{-/-}$mice was unexpected. It has been previously documented that increasing numbers of plasma cells are found in the tissues of diseased mdr1 $\mathrm{a}^{-/-}$mice [58]. Given that HGEE treated mdr1a $\mathrm{a}^{-/-}$mice exhibited significantly less severe colitic disease, it is unclear what caused the increase in plasma cells in the cecal and colonic tissues of these mice nor what the role of these plasma cells would be in the attenuation of lesion severity. In the absence of inflammation, HGEE treatment did not increase the numbers of plasma cells in the mucosa of $\mathrm{FVB}^{\mathrm{WT}}$ mice indicating that there is no direct cause or effect related to the HGEE treatment and the increase in mucosal plasma cells.

Table 1 Colon histopathology scores

\begin{tabular}{|c|c|c|c|}
\hline Microscopic Parameter & $\begin{array}{l}\text { FVB } \\
\text { Vehicle } \\
(n=6)\end{array}$ & $\begin{array}{l}\text { Mdr1 } 1^{-/-} \\
\text {Vehicle } \\
(n=16)\end{array}$ & $\begin{array}{l}\text { Mdr1 }^{-/-} \\
\text {HGEE } \\
(n=16)\end{array}$ \\
\hline Mucosal Height $(\mu \mathrm{m})$ & $3.2 \pm 0.2^{b}$ & $5.2 \pm 0.2$ & $4.9 \pm 0.2$ \\
\hline Ulceration & $0.0 \pm 0.0^{b}$ & $1.9 \pm 0.3$ & $1.3 \pm 0.3$ \\
\hline Inflammation & $1.0 \pm 0.0^{b}$ & $3.5 \pm 0.2$ & $3.2 \pm 0.3$ \\
\hline Edema & $0.2 \pm 0.2$ & $1.2 \pm 0.3$ & $0.4 \pm 0.2$ \\
\hline Stromal Collapse (Necrosis) & $0.0 \pm 0.0$ & $1.1 \pm 0.3$ & $1.0 \pm 0.2$ \\
\hline Gland Hyperplasia & $0.3 \pm 0.2^{b}$ & $3.0 \pm 0.2$ & $3.0 \pm 0.2$ \\
\hline Additive Colonic Score & $4.6 \pm 0.2^{b}$ & $15.9 \pm 0.9$ & $13.8 \pm 1.1$ \\
\hline $\begin{array}{l}\text { \% Mice Exhibiting Colonic Neutrophil } \\
\text { Infiltrate }\end{array}$ & $0 \%{ }^{b}$ & $100 \%$ & $69 \% \%^{c}$ \\
\hline $\begin{array}{l}\text { \% Mice Exhibiting Colonic Plasma Cell } \\
\text { Infiltrate }\end{array}$ & $0 \%$ & $12 \%$ & $31 \%$ \\
\hline
\end{tabular}


Table 2 Cecum Histopathology Scores

\begin{tabular}{|c|c|c|c|}
\hline Microscopic Parameter & $\begin{array}{l}\text { FVB } \\
\text { Vehicle } \\
(n=6)\end{array}$ & $\begin{array}{l}\text { Mdr1 }^{-/-} \\
\text {Vehicle } \\
(n=16)\end{array}$ & $\begin{array}{l}\text { Mdr1 }^{-/-} \\
\text {HGEE } \\
(n=16)\end{array}$ \\
\hline Mucosal Height $(\mu \mathrm{m})$ & $3.7 \pm 0.2$ & $4.5 \pm 0.2$ & $4.6 \pm 0.2$ \\
\hline Ulceration & $0.0 \pm 0.0^{b}$ & $2.3 \pm 0.3$ & $0.7 \pm 0.3^{\mathrm{a}}$ \\
\hline Inflammation & $1.5 \pm 0.3^{b}$ & $3.2 \pm 0.2$ & $3.1 \pm 0.2$ \\
\hline Edema & $1.3 \pm 0.3$ & $2.1 \pm 0.2$ & $1.6 \pm 0.3$ \\
\hline Stromal Collapse (Necrosis) & $0.0 \pm 0.0^{b}$ & $1.7 \pm 0.3$ & $0.6 \pm 0.3^{\mathrm{a}}$ \\
\hline Gland Hyperplasia & $0.7 \pm 0.3^{b}$ & $2.8 \pm 0.3$ & $2.6 \pm 0.2$ \\
\hline Additive Cecal Score & $7.2 \pm 0.8^{b}$ & $16.4 \pm 1.2$ & $13.1 \pm 1.0^{\mathrm{c}}$ \\
\hline $\begin{array}{l}\text { \% Mice Exhibiting Cecal } \\
\text { Neutrophil Infiltrate }\end{array}$ & $0 \%{ }^{b}$ & $81 \%$ & $56 \%$ \\
\hline $\begin{array}{l}\text { \% Mice Exhibiting Cecal } \\
\text { Plasma Cell Infiltrate }\end{array}$ & $0 \%$ & $12 \%$ & $31 \%$ \\
\hline
\end{tabular}

Data are expressed as the mean \pm SEM. ${ }^{\mathrm{a}} \mathrm{p}<0.05,{ }^{\mathrm{b}} \mathrm{p}<0.01$ as compared to $\mathrm{mdr} 1 \mathrm{a}^{-/-}$vehicle with a Kruskal-Wallis test. ${ }^{\mathrm{c}} \mathrm{p}<0.05$ as compared to $\mathrm{mdr}^{1 \mathrm{a}^{-/-}}$vehicle with a Mann-Whitney test.

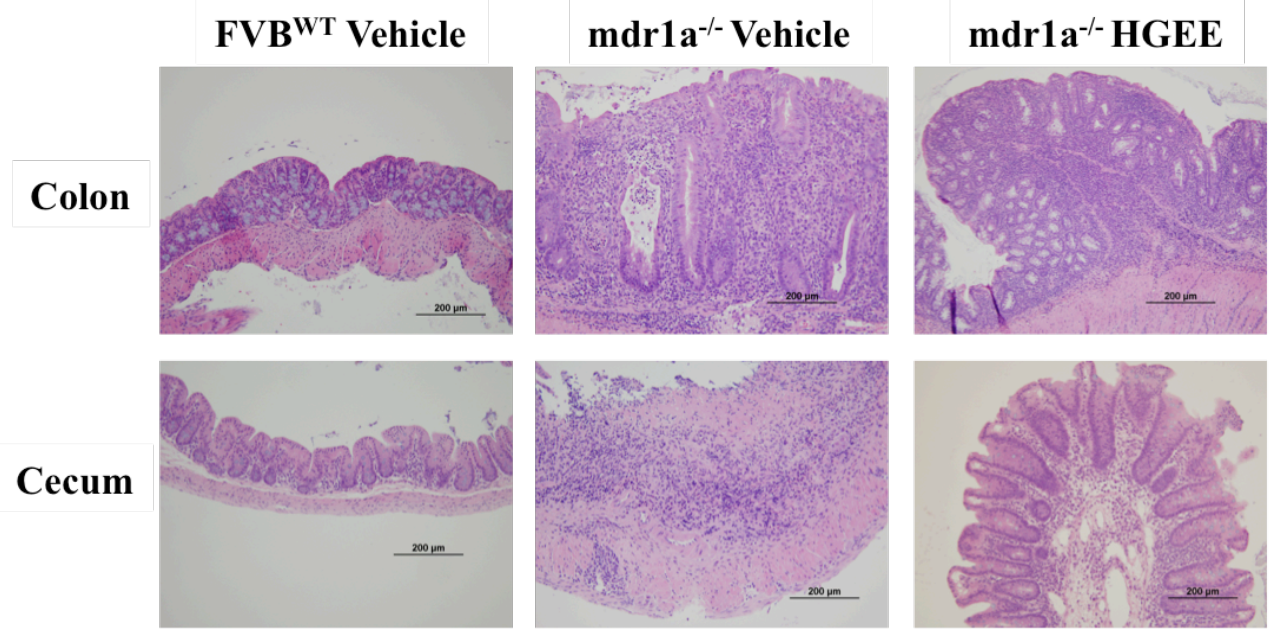

Figure 4 HGEE protects microscopic architecture in mdrla-/- mice, decreases inflammatory cell infiltrate, and increases plasma cell infiltrate. Representative photomicrographs (200x) of cecal and colonic sections collected from $\mathrm{mdr} \mathrm{a}^{-/-}$and $\mathrm{FVB}^{\mathrm{WT}}$ mice treated with vehicle or HGEE at the time of necropsy were formalin fixed, paraffin embedded and subject to routine hematoxylin and eosin staining. Photographs were chosen based on the average macroscopic and microscopic score data for each group and are representative of two independent experiments (see Figure 2 for number of animals in each treatment group). 
As a measure of inflammation and infiltration of granulocytes into the mucosal tissue, MPO activity was measured in colonic and cecal homogenates (Figure 5). In comparison to tissue samples from the vehicle-treated $\mathrm{mdrla}^{-/-}$mice, the associated MPO enzymatic activity was significantly diminished in colons of HGEE treated mdr1 $\mathrm{a}^{-/-}$mice $(\mathrm{p}<0.05)$ (Figure 5A). In addition, cecal tissue of HGEE treated $\mathrm{mdr}^{-/ /} \mathrm{a}^{-/}$mice presented with less MPO activity consistent with the less severe histologically scores and less prominent neutrophilic infiltration (Figure 5B).
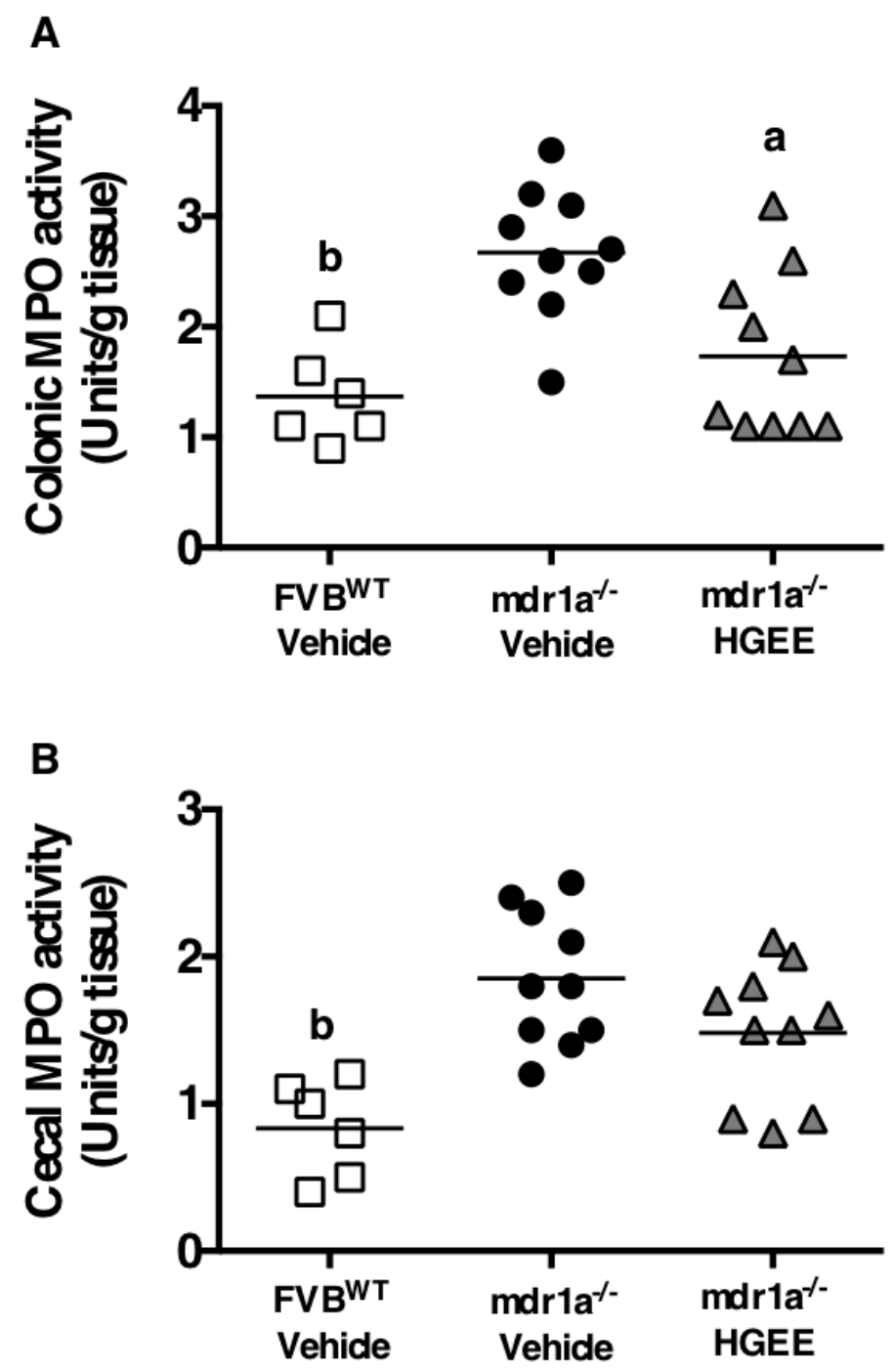

Figure 5 Metronidazole and HGEE reduce local myeloperoxidase (MPO) activity in the colons (A) and ceca (B) of mdr1a-/- mice. Homogenates of colonic or cecal tissue were used to assay for MPO activity. ${ }^{\mathrm{a}} \mathrm{p}<0.05,{ }^{\mathrm{b}} \mathrm{p}<0.01$ as compared to $\mathrm{mdr} 1 \mathrm{a}^{-/}$vehicle with a Kruskal-Wallis test. Data is representative of: $\mathrm{FVB}^{\mathrm{WT}}$ vehicle $\mathrm{n}=6, \mathrm{mdr}^{-\mathrm{a}^{-/}}$vehicle $\mathrm{n}=10, \operatorname{HGEE} \mathrm{n}=10$.

Together, these data suggest that the ability of orally administered HGEE to reduce neutrophil infiltration and increase lamina proprial plasma cells in the ceca and colons correlated with less severe inflammation and tissue injury that is characteristically associated with the spontaneous colitis that develops in untreated $\mathrm{mdr} 1 \mathrm{a}^{-/-}$mice. 
Impact of the ethanolic extract of $\boldsymbol{H}$. gentianoides on the induction of chemotactic and proinflammatory cytokines

To further investigate inflammatory modulation related to improved macroscopic and microscopic cecal and colonic health, serum samples collected at necropsy were examined for the presence of cytokines and chemokines. Many analytes including G-CSF, IL-6, CXCL10, KC, CXCL9, and TNF $\alpha$ were significantly $(\mathrm{p}<0.01)$ elevated in vehicle-treated $\mathrm{mdr}^{-/-}$mice compared to FVB ${ }^{\mathrm{WT}}$ controls (Table 3 ). G-CSF, KC, and TNF $\alpha$ were significantly $(\mathrm{p}<0.05)$ lower in HGEE treated mdr $1 \mathrm{a}^{-/-}$mice (Table 3 ). It is clear from these data that the production of chemokines and inflammatory cytokines were reduced in HGEE treated $\mathrm{mdr} 1 \mathrm{a}^{-/-}$mice.

Table 3 Serum cytokine analysis

\begin{tabular}{|c|c|c|c|}
\hline $\begin{array}{l}\text { Cytokine/ } \\
\text { Chemokine }\end{array}$ & $\begin{array}{l}\text { FVB }^{W T} \\
\text { Vehicle } \\
(n=6)\end{array}$ & $\begin{array}{l}\text { Mdr1 }^{-/-} \\
\text {Vehicle } \\
(n=16)\end{array}$ & $\begin{array}{c}\text { Mdr1 }^{-/-} \\
\text {gentianoides } \\
(\mathrm{n}=16)\end{array}$ \\
\hline G-CSF & $156 \pm 43^{b}$ & $7944 \pm 2635$ & $2009 \pm 625^{\mathrm{a}}$ \\
\hline GM-CSF & $17 \pm 2$ & $18 \pm 3$ & $15 \pm 3$ \\
\hline IL-1及 & $104 \pm 17$ & $133 \pm 13$ & $105 \pm 15$ \\
\hline IL-6 & $9 \pm 3^{b}$ & $149 \pm 56$ & $230 \pm 117$ \\
\hline IL-10 & $18 \pm 4$ & $20 \pm 2$ & $28 \pm 9$ \\
\hline IL-12(p40) & $29 \pm 4$ & $85 \pm 35$ & $100 \pm 36$ \\
\hline IL-12(p70) & $49 \pm 8$ & $39 \pm 7$ & $31 \pm 6$ \\
\hline IL-13 & $518 \pm 68$ & $475 \pm 45$ & $383 \pm 46$ \\
\hline CXCL10 & $25 \pm 5^{b}$ & $612 \pm 151$ & $361 \pm 80$ \\
\hline KC & $125 \pm 31^{b}$ & $801 \pm 122$ & $251 \pm 30^{\mathrm{a}}$ \\
\hline CXCL9 & $73 \pm 19^{b}$ & $2119 \pm 469$ & $1461 \pm 248$ \\
\hline TNFa & $\mathbf{N D}^{\mathbf{b}}$ & $12 \pm 2$ & $7 \pm 1^{c}$ \\
\hline
\end{tabular}

Data results are expressed as the mean serum cytokine/chemokines content $(\mathrm{pg} / \mathrm{mL}) \pm \mathrm{SEM} .{ }^{\mathrm{a}} \mathrm{p}<$ $0.05,{ }^{b} \mathrm{p}<0.01$ as compared to $\mathrm{mdr} 1 \mathrm{a}^{-/-}$vehicle with a Kruskal-Wallis test. ${ }^{\mathrm{c}} \mathrm{p}<0.05$ as compared to $\operatorname{mdr} 1 \mathrm{a}^{-/-}$vehicle with a $t$-test. ND $=$ Not detected

Analysis of the levels of serum cytokine from HGEE treated mdrla $\mathrm{a}^{-/-}$mice further supports the anti-inflammatory potential of this botanical extract. HGEE treatment of $\mathrm{mdrla}^{-/-}$mice resulted in a significant reduction in the detection of G-CSF, KC, and TNF $\alpha$. G-CSF and KC are both stimulatory and chemoattractant for neutrophils [59, 60]. Their downregulation by HGEE treatment is consistent with the decrease in colonic and cecal neutrophil infiltrate seen in HGEE treated $\mathrm{mdrla}^{-/-}$mice. HGEE reduction of $\mathrm{TNF} \alpha$ serum concentrations is a compelling observation, as TNF $\alpha$ has been directly implicated in the pathogenesis and chronicity of IBD 
[61]. TNF $\alpha$ has previously been shown to be elevated in untreated $m d r 1 \mathrm{a}^{-/-}$mice [47]. There was a trend for the presence of increased levels of IL-6 in the sreum of HGEE treated mdr $1 \mathrm{a}^{-/-}$mice. Depending on the cytokine milieu of the mucosal microenvironment, it should be noted that IL-6 can be either pro-inflammatory or anti-inflammatory by enhancing T helper 17 cell development or regulatory $\mathrm{T}$ cell development, respectively [62]. The potential benefits of elevated IL-6 is supported by a recent study which reported that IL-6 levels are elevated in the tissues of human patients with active IBD in the absence of microscopic and macroscopic inflammation suggesting active immune regulation even in the absence of demonstrable inflammation [63]. The observed reduction in the levels of cytokine/chemokines noted in the present study is consistent with the amelioration of microscopic and macroscopic lesions and can be related to the associated reduction in granulocyte and neutrophil activity in HGEE treated $\mathrm{mdr} 1 \mathrm{a}^{-/-}$mice.

\section{CONCLUSIONS}

In summary, the ethanolic extract of Hypericum gentianoides was shown to possess antiinflammatory and immunomodulatory potential based on its ability to attenuate inflammation in mdrla-/- mice that develop spontaneous colitis. This activity is likely related to the flavonoid and polyphenolic compounds in the extract. Our work highlights the need for further study (e.g., increased doses per day) of HGEE, the potential synergy of its active components, and its efficacy in other inflammatory disease models. Because of the spontaneous (i.e., genetic) nature of this model, it better represents human IBD than chemically-induced models of colitis and provides a basis for evaluating the medicinal benefits of CAM products.

Abbreviations: Complementary and alternative medicine (CAM), Hypericum gentianoides (HG), Hypericum gentianoides ethanolic extract (HGEE), myeloperoxidase (MPO), Inflammatory Bowel Disease (IBD), anti-tumor necrosis factor alpha (Anti-TNF $\alpha$ ), Ethanol $(\mathrm{EtOH})$

Competing Interests: The authors have no financial interests or conflicts of interest.

Author's Contributions: KH, AR-T, and MW designed the research; KH and MWB performed the research; $\mathrm{CH}$ and $\mathrm{PM}$ prepared the extract; JH provided histopathological analysis; $\mathrm{KH}$ and MWB analyzed the data; KH, MWB, AR-T, and MW prepared the manuscript, figures, and data analysis.

Acknowledgements and Funding: The authors thank Dr. Philip Dixon for helpful discussion and review of the statistics. This research was supported by NIH (9P50 AT004155-06).

\section{REFERENCES}

1. C Abraham, JH Cho: Inflammatory bowel disease. N Engl J Med 2009, 361: 20662078.

2. BA Hendrickson, R Gokhale, JH Cho: Clinical aspects and pathophysiology of inflammatory bowel disease. Clin Microbiol Rev 2002, 15: 79-94. 
3. MD Kappelman, et al.: The prevalence and geographic distribution of Crohn's disease and ulcerative colitis in the United States. Clin Gastroenterol Hepatol 2007, 5: 14241429.

4. L Lakatos, et al.: Striking elevation in incidence and prevalence of inflammatory bowel disease in a province of western Hungary between 1977-2001. World J Gastroenterol 2004, 10: 404-409.

5. KT Thia, EV Loftus, Jr., WJ Sandborn, SK Yang: An update on the epidemiology of inflammatory bowel disease in Asia. Am J Gastroenterol 2008, 103: 3167-3182.

6. JK Triantafillidis, E Merikas, F Georgopoulos: Current and emerging drugs for the treatment of inflammatory bowel disease. Drug Des Devel Ther 2010, 5: 185-210.

7. AW Lim, R Panaccione, $\mathrm{CH}$ Seow: Exploring the role of monitoring anti-TNFalpha drug and antibody levels in the management of inflammatory bowel disease. Therap Adv Gastroenterol 2011, 4: 145-151.

8. WJ Sandborn, et al.: Adalimumab induction therapy for Crohn disease previously treated with infliximab: a randomized trial. Ann Intern Med 2007, 146: 829-838.

9. P Rutgeerts, et al.: Infliximab for induction and maintenance therapy for ulcerative colitis. N Engl J Med 2005, 353: 2462-2476.

10. SB Hanauer, et al.: Maintenance infliximab for Crohn's disease: the ACCENT I randomised trial. Lancet 2002, 359: 1541-1549.

11. G Van Assche, et al.: Progressive multifocal leukoencephalopathy after natalizumab therapy for Crohn's disease. N Engl J Med 2005, 353: 362-368.

12. BE Sands, et al.: Infliximab maintenance therapy for fistulizing Crohn's disease. N Engl J Med 2004, 350: 876-885.

13. M Frass, et al.: Use and acceptance of complementary and alternative medicine among the general population and medical personnel: a systematic review. Ochsner J 2012, 12: 45-56.

14. P Rawsthorne, et al.: An international survey of the use and attitudes regarding alternative medicine by patients with inflammatory bowel disease. Am J Gastroenterol 1999, 94: 1298-1303.

15. J Langhorst, et al.: Amount of systemic steroid medication is a strong predictor for the use of complementary and alternative medicine in patients with inflammatory bowel disease: results from a German national survey. Inflamm Bowel Dis 2005, 11: 287-295.

16. S Joos: Review on efficacy and health services research studies of complementary and alternative medicine in inflammatory bowel disease. Chin J Integr Med 2011, 17: 403409.

17. P Vuorelaa, et al.: Natural products in the process of finding new drug candidates. Curr Med Chem 2004, 11: 1375-1389.

18. LN Jackson, Y Zhou, S Qiu, Q Wang, BM Evers: Alternative medicine products as a novel treatment strategy for inflammatory bowel disease. Am J Chin Med 2008, 36: 953-965.

19. EM Williamson: Synergy and other interactions in phytomedicines. Phytomedicine 2001, 8: 401-409. 
20. KM Haarberg, et al.: Orally administered extract from Prunella vulgaris attenuates spontaneous colitis in mdrla(-/-) mice. World J Gastrointest Pharmacol Ther 2015, 6: 223-237.

21. F Conforti, GA Statti, R Tundis, F Menichini, P Houghton: Antioxidant activity of methanolic extract of Hypericum triquetrifolium Turra aerial part. Fitoterapia 2002, 73: 479-483.

22. J Benedi, R Arroyo, C Romero, S Martin-Aragon, AM Villar: Antioxidant properties and protective effects of a standardized extract of Hypericum perforatum on hydrogen peroxide-induced oxidative damage in PC12 cells. Life Sci 2004, 75: 1263-1276.

23. SM Lavagna, et al.: Efficacy of Hypericum and Calendula oils in the epithelial reconstruction of surgical wounds in childbirth with caesarean section. Farmaco 2001, 56: 451-453.

24. B Ozturk, S Apaydin, E Goldeli, I Ince, U Zeybek: Hypericum triquetrifolium Turra. Extract exhibits antiinflammatory activity in the rat. J Ethnopharmacol 2002, 80: 207209.

25. AF Viana, AP Heckler, R Fenner, SM Rates: Antinociceptive activity of Hypericum caprifoliatum and Hypericum polyanthemum (Guttiferae). Braz J Med Biol Res 2003, 36: 631-634.

26. Y Wu, SD Zhou, P Li: Determination of flavonoids in Hypericum perforatum by HPLC analysis. Yao Xue Xue Bao 2002, 37: 280-282.

27. R Berghofer, J Holzl: Biflavonoids in Hypericum perforatum; Part 1. Isolation of I3, II8-Biapigenin. Planta Med 1987, 53: 216-217.

28. KH Kwon, A Murakami, T Tanaka, H Ohigashi: Dietary rutin, but not its aglycone quercetin, ameliorates dextran sulfate sodium-induced experimental colitis in mice: attenuation of pro-inflammatory gene expression. Biochem Pharmacol 2005, 69: 395406.

29. T Dost, H Ozkayran, F Gokalp, C Yenisey, M Birincioglu: The effect of Hypericum perforatum (St. John's Wort) on experimental colitis in rat. Dig Dis Sci 2009, 54: 12141221.

30. F Danesi, M Philpott, C Huebner, A Bordoni, LR Ferguson: Food-derived bioactives as potential regulators of the IL-12/IL-23 pathway implicated in inflammatory bowel diseases. Mutat Res 2010, 690: 139-144.

31. M Jung, S Triebel, T Anke, E Richling, G Erkel: Influence of apple polyphenols on inflammatory gene expression. Mol Nutr Food Res 2009, 53: 1263-1280.

32. V Butterweck, M Schmidt: St. John's wort: role of active compounds for its mechanism of action and efficacy. Wien Med Wochenschr 2007, 157: 356-361.

33. A Boiy, R Roelandts, J van den Oord, PA de Witte: Photosensitizing activity of hypericin and hypericin acetate after topical application on normal mouse skin. Br J Dermatol 2008, 158: 360-369.

34. P Bradley, D Priebat, R Christensen, G Rothstein: Measurement of cutaneous inflammation: estimation of neutrophil content with an enzyme marker. Journal of Investigative Dermatology 1982, 78: 206-209. 
35. JA Cotterill: Severe phototoxic reaction to laser treatment in a patient taking St John's Wort. J Cosmet Laser Ther 2001, 3: 159-160.

36. PB Hamel, MU Chiltosky: Cherokee Plants and Their Uses - A 400 Year History. Sylva: Herald Publishing Company; 1975.

37. SL Crockett, B Schaneberg, IA Khan: Phytochemical profiling of New and Old World Hypericum (St. John's Wort) species. Phytochem Anal 2005, 16: 479-485.

38. ML Hillwig, KD Hammer, DF Birt, ES Wurtele: Characterizing the metabolic fingerprint and anti-inflammatory activity of Hypericum gentianoides. J Agric Food Chem 2008, 56: 4359-4366.

39. N Huang, et al.: Identification of anti-inflammatory constituents in Hypericum perforatum and Hypericum gentianoides extracts using RAW 264.7 mouse macrophages. Phytochemistry 2011, 72: 2015-2023.

40. J Barnes, L Anderson, J Phillipson: Saint John's wort (Hypericum perforatum L.): a review of its chemistry, pharmacology and clinical properties. J. Pharm. Pharmacol. 2001, 53: 583-600.

41. AE Jergens, et al.: Induction of differential immune reactivity to members of the flora of gnotobiotic mice following colonization with Helicobacter bilis or Brachyspira hyodysenteriae. Microbes Infect 2006, 8: 1602-1610.

42. AE Jergens, et al.: Helicobacter bilis triggers persistent immune reactivity to antigens derived from the commensal bacteria in gnotobiotic $\mathrm{C} 3 \mathrm{H} / \mathrm{HeN}$ mice. Gut 2007, 56: 934-940.

43. Z Ye, et al.: Increased CYP4B1 mRNA is associated with the inhibition of dextran sulfate sodium-induced colitis by caffeic acid in mice. Exp Biol Med (Maywood) 2009, 234: 605-616.

44. CM Panwala, JC Jones, JL Viney: A novel model of inflammatory bowel disease: mice deficient for the multiple drug resistance gene, mdrla, spontaneously develop colitis. J Immunol 1998, 161: 5733-5744.

45. JN Wilk, J Bilsborough, JL Viney: The mdrla-/- mouse model of spontaneous colitis: a relevant and appropriate animal model to study inflammatory bowel disease. Immunol Res 2005, 31: 151-159.

46. A Collett, et al.: Early molecular and functional changes in colonic epithelium that precede increased gut permeability during colitis development in mdr1a(-/-) mice. Inflamm Bowel Dis 2008, 14: 620-631.

47. Y Masunaga, et al.: Expression profiles of cytokines and chemokines in murine MDR1a-/- colitis. Inflamm Res 2007, 56: 439-446.

48. J Bilsborough, JL Viney: Out, out darn toxin: the role of MDR in intestinal homeostasis. Gastroenterology 2004, 127: 339-340.

49. M Schwab, et al.: Association between the C3435T MDR1 gene polymorphism and susceptibility for ulcerative colitis. Gastroenterology 2003, 124: 26-33.

50. K Anezaki, et al.: Correlations between interleukin-8, and myeloperoxidase or luminoldependent chemiluminescence in inflamed mucosa of ulcerative colitis. Intern Med 1998, 37: 253-258. 
51. SW Edwards, TF Swan: Regulation of superoxide generation by myeloperoxidase during the respiratory burst of human neutrophils. Biochem J 1986, 237: 601-604.

52. I Masoodi, et al.: Fecal lactoferrin, myeloperoxidase and serum C-reactive are effective biomarkers in the assessment of disease activity and severity in patients with idiopathic ulcerative colitis. J Gastroenterol Hepatol 2009, 24: 1768-1774.

53. M Lampinen, P Sangfelt, Y Taha, M Carlson: Accumulation, activation, and survival of neutrophils in ulcerative colitis: regulation by locally produced factors in the colon and impact of steroid treatment. Int J Colorectal Dis 2008, 23: 939-946.

54. D Latinne, R Fiasse: New insights into the cellular immunology of the intestine in relation to the pathophysiology of inflammatory bowel diseases. Acta Gastroenterol Belg 2006, 69: 393-405.

55. PPEv Lierop, et al.: T-cell regulation of neutrophil infiltrate at the early stages of a murine colitis model. Inflammatory Bowel Diseases 2010, 16: 442-451.

56. Y Morohoshi, et al.: Inhibition of neutrophil elastase prevents the development of murine dextran sulfate sodium-induced colitis. J Gastroenterol 2006, 41: 318-324.

57. KL Mumy, BA McCormick: The role of neutrophils in the event of intestinal inflammation. Curr Opin Pharmacol 2009, 9: 697-701.

58. L Maggio-Price, et al.: Helicobacter bilis infection accelerates and $H$. hepaticus infection delays the development of colitis in multiple drug resistance-deficient (mdr1a/-) mice. Am J Pathol 2002, 160: 739-751.

59. KC Queiroz, et al.: Tissue factor-dependent chemokine production aggravates experimental colitis. Mol Med 2011,

60. M Khajah, B Millen, DC Cara, C Waterhouse, DM McCafferty: Granulocytemacrophage colony-stimulating factor (GM-CSF): a chemoattractive agent for murine leukocytes in vivo. J Leukoc Biol 2011, 89: 945-953.

61. H Schmitz, et al:: Tumor necrosis factor-alpha induces $\mathrm{Cl}-$ and $\mathrm{K}+$ secretion in human distal colon driven by prostaglandin E2. Am J Physiol 1996, 271: G669-674.

62. K Mitsuyama, et al.: Therapeutic strategies for targeting the IL-6/STAT3 cytokine signaling pathway in inflammatory bowel disease. Anticancer Res 2007, 27: 37493756.

63. P Drastich, L Frolova-Brizova, P Zanvit, J Spicak, H Tlaskalova-Hogenova: Spontaneous in vitro IL-6 production in various intestinal segments in patients with inflammatory bowel disease. Folia Microbiol (Praha) 2011, 56: 185-190. 